\title{
Exposure to hog barn dust alters airway epithelial ciliary beating
}

\author{
T.A. Wyatt*\#, J.H. Sisson*, S.G. Von Essen*, J.A. Poole* and D.J. Romberger*,\#
}

\begin{abstract}
Swine confinement workers are at increased risk of airway diseases, including mucus membrane irritation syndrome, chronic rhinosinusitis and chronic bronchitis. Dust extracts from swine confinement facilities stimulate the production of pro-inflammatory cytokines in bronchial epithelial cells, including interleukin (IL)-8. As IL-8 is capable of blocking $\beta$-agoniststimulated increases in cilia beating, which impacts on mucociliary clearance, it was hypothesised that hog barn-dust exposure might alter cilia responses to stimulation.

To test this hypothesis, ciliated bovine bronchial epithelial cell cultures were exposed to hog barn-dust extract (HDE) and ciliary beat frequency (CBF) was assayed.

An elevation in baseline CBF was observed. This effect appeared to be independent of endotoxin but dependent upon nitric oxide. HDE also stimulated nitric oxide production in bronchial epithelial cells; however, stimulation of cilia beating by a $\beta$-agonist did not occur in cells pre-exposed to HDE.

These data demonstrate that hog barn dust can alter normal stimulation of cilia, suggesting a mechanism for the abrogation of stimulated increases in mucociliary clearance in response to inhaled dust exposure.
\end{abstract}

KEYWORDS: Airway epithelial cells, cilia, hog barn dust, swine confinement

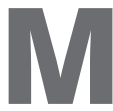

odern swine operations raise hundreds to thousands of animals in closed confinement buildings, raising concern over the occupational, environmental and community hazards posed by these large concentrated animal feeding operations [1]. This method of raising swine has become the major workplace activity for a number of agricultural workers. The air in swine confinement barns often has high levels of ammonia and dust that is rich in endotoxin [2]. Endotoxin, ammonia and high total dust levels are associated with the presence of airway disease in these workers $[2,3]$. Swine confinement workers commonly report increased nasal and sinus symptoms, cough, chest tightness, wheezing and shortness of breath upon exertion [4]. These symptoms are associated with the presence of airflow obstruction on pulmonary function tests and evidence of lower respiratory tract inflammation $[2,3,5]$. Significant upper respiratory tract inflammation also occurs and is marked by increased neutrophils and inflammatory cytokines in the nasal lavage of normal volunteers exposed to swine confinement facilities [6, 7]. Furthermore, exposed workers commonly experience nasal congestion, chronic sinonasal disease and reduced sense of smell [8]. However, little is known about the effects of work in swine confinement barns on mucociliary clearance.
Mucociliary clearance is a regulable innate host defence that consists of a complex regulation of secreted mucus, airway surface liquid and ciliary beating [9]. The stimulation of mammalian ciliary beating involves a nitric oxide (NO)-mediated process [10] that regulates cyclic nucleotidedependent pathways [11]. $\beta$-agonists have been widely used to stimulate an increase in cilia beat for in vitro studies [12]. It has previously been identified that the $\beta$-agonist stimulation of cilia beat can be desensitised by exposure to alcohol [13] or blocked by the presence of interleukin (IL)-8 [14]. Previously, in vitro studies have shown that hog barn dust stimulates the production of IL- 6 and IL-8 in human bronchial epithelial cells [15]. This response was independent of the endotoxin concentrations present in the dust and required the activation of protein kinase $\mathrm{C}$.

As swine confinement workers are at an increased risk of developing upper and lower respiratory tract airway diseases, it was hypothesised that one innate defence mechanism, mucociliary clearance, may be altered in ciliated epithelial cells exposed to swine confinement facility dust. Exposure of airway epithelium to hog barn dust results in the production of IL-8; thus, the present authors further hypothesised

\section{AFFILIATIONS}

*Dept of Internal Medicine

Pulmonary, Critical Care, Sleep and Allergy Section, University of Nebraska Medical Center, and *Omaha Veterans Affairs Medical Center, Research Center, Omaha, NE, USA

CORRESPONDENCE

T.A. Wyatt

Dept of Internal Medicine

Pulmonary, Critical Care, Sleep and Allergy Section

University of Nebraska Medical

Center

Omaha

NE 68198-5300

USA

Fax: 14025596584

E-mail: twyatt@unmc.edu

Received:

February 062007

Accepted after revision:

January 072008

\section{SUPPORT STATEMENT}

J.H. Sisson was supported by a grant from the National Institutes of Health (2R01AA008769). The Dept of Veterans Affairs gave Merit Review Grants to T.A. Wyatt and D.J. Romberger. Centers for Disease Control and Prevention (CDC)/The National Institute for Occupational Safety and Health (NIOSH) gave a grant to D.J. Romberger (1R01H008539). This work's contents are solely the responsibility of the authors and do not necessarily represent the official view of the funding agencies. T.A. Wyatt is an American Lung Association Career Investigator.

STATEMENT OF INTEREST None declared 
that such exposure would block the stimulatory effect of $\beta$ agonists on cilia beating. These mechanistic studies of in vitro cilia beating provide an insight into the effects of working in a swine confinement environment on the respiratory tract.

\section{MATERIALS AND METHODS Cell preparation}

To model particle stimulation of cilia in vivo, bovine ciliated epithelial cells were stimulated with $\beta$-agonists to increase cilia beating in vitro. Primary bovine bronchial epithelial cells were prepared from bovine lung as described previously [16]. Bronchi were necropsied from the lung and digested overnight at $4{ }^{\circ} \mathrm{C}$ in $0.1 \%$ bacterial protease type IV in minimum essential media (M199 with Earl's salts; Invitrogen, Carlsbad, CA, USA). The following day, the bronchi were repeatedly rinsed in M199 containing 10\% foetal bovine serum (FBS; Invitrogen) to collect the epithelial cells lining the lumen. Ciliated clump cells were collected by a $40-\mu \mathrm{m}$ mesh filter, which has been shown to effectively isolate $>95 \%$ viable ciliated cells in the flow through. These cells were then washed in M199 media, counted with a haemocytometer and $3 \times 10^{6}$ cells were plated on $60-\mathrm{mm}$ tissue culture dishes coated with $1 \%$ type I collagen (Vitrogen; Cohesion, Palo Alto, CA, USA). Cells were grown in M199 complete media containing $10 \%$ FBS, $50 \mathrm{U} \cdot \mathrm{mL}^{-1}$ penicillin and streptomycin (Invitrogen) and $2 \mu \mathrm{g} \cdot \mathrm{mL}^{-1}$ fungizone (Invitrogen), in a humidified $95 \%$ air $/ 5 \% \mathrm{CO}_{2}$ incubator at $37^{\circ} \mathrm{C}$. Confluent monolayers of primary ciliated cells were obtained in 3 days and treated as described.

\section{Preparation of hog barn-dust extract}

Settled dust was collected $\sim 1-2 \mathrm{~m}$ above the floor from swine confinement buildings with $\sim 500-700$ swine weighing $\sim 100 \mathrm{~kg}$ [17]. The dust from each facility was processed separately and experiments were repeated using different sources of dust, including freshly obtained dust and dust that was stored at $80^{\circ} \mathrm{C}$. The extract was prepared in a similar fashion to grain dust extracts utilised in previously published studies [18] and to hog barn-dust extract (HDE) used in animal model studies [19]. HDE was prepared by placing $1 \mathrm{~g}$ of dust in $10 \mathrm{~mL}$ of Hank's balanced salt solution (Biosource International, Camarillo, CA, USA) without calcium. The mixture was vortexed and allowed to stand at room temperature for $1 \mathrm{~h}$. The mixture was centrifuged for $20 \mathrm{~min}$ at $2,000 \times g$, supernatant was recovered and centrifuged again for $20 \mathrm{~min}$ at $2,000 \times g$. The final supernatant was filter sterilised and used immediately. This supernatant was considered as 100\% HDE and diluted into culture medium to achieve the various HDE concentrations used in the experiments.

Other studies have reported culturable bacteria of $0.3 \times 10^{4}-$ $3.3 \times 10^{8}$ colony-forming units $(\mathrm{cfu}) \cdot \mathrm{m}^{-3}$ in workers' breathing zones [20]. The present authors cultured $\sim 5 \times 10^{6} \mathrm{cfu} \cdot \mathrm{g}^{-1}$ of hog barn dust used to produce $100 \%$ HDE. This suggested that the concentration of culturable bacteria in the HDE was similar to the concentration of bacteria in the breathing zone of workers.

The extract made with hog feed from a matching swine confinement facility, or grain feed-dust extract (GFDE), was prepared in an identical fashion to the HDE. The amount of endotoxin in HDE was quantitated using the Limulus amebocyte lysate (LAL) gel clot assay (Cambrex, Walkersville, MD, USA) and recorded on each prepared extract [21].
Endotoxin-reduced HDE (40 endotoxin units $(\mathrm{EU}) \cdot \mathrm{mL}^{-1}$ preversus $0.06 \mathrm{EU} \cdot \mathrm{mL}^{-1}$ post-polymyxin $\mathrm{B}$ ) was prepared and characterised as previously described [15].

\section{Ciliary beat frequency assay}

Cells were maintained at a constant temperature $\left(25 \pm 0.5^{\circ} \mathrm{C}\right)$ during all experimental procedures with the use of a thermostatically controlled heated stage. The motion of cilia was processed using the Sisson-Ammons Video Analysis (SAVA) system (Ammons Engineering, Mt Morris, MI, USA) as described previously [22]. Images of ciliated cells were visualised on an Olympus IMT-2 inverted phase-contrast microscope (Olympus, Tokyo, Japan) using a $20 \times$ objective lens with a $1.5 \times$ tube multiplier, and images were captured using a Kodak 310 analog/digital video camera (Eastman Kodak Motion Analysis System Division, San Diego, CA, USA). The sampling rate was set at 85 frames $\cdot \mathrm{s}^{-1}$ for all experimental conditions. Captured digital video was transmitted from the camera directly into an IMACQ OCI/PXI-1422 digital acquisition board (National Instruments, Austin, TX, USA) within a Dell Precision 420 Workstation. The entire captured image of $640 \times 480$ pixels was automatically analysed for motion by SAVA using a process known as Whole Field Analysis. The Whole Field Analysis technique has been validated against specific region-of-interest analysis as described previously [22]. The SAVA software analysed each image, containing 19,200 possible motile zones, to determine the average frequency and the SEM for each field captured. For each experimental condition, a minimum of six separate fields were captured, analysed and expressed as a data point. ANOVA was run on each data point and was considered significant with a $\mathrm{p}$-value $\leqslant 0.05$.

\section{NO analysis}

Bronchial epithelial cell NO production was monitored via the detection of $\mathrm{NO}$ by a gas-phase chemiluminescent reaction between $\mathrm{NO}$ and ozone $\left(\mathrm{O}_{3}\right.$; Sievers Instruments Model 280i; GE Analytical Instruments, Boulder, CO, USA). Monolayers of airway epithelial cells were treated with various concentrations of HDE for various times. The cell medium was separated from the cells and both fractions flash frozen to halt metabolic reactions. The proteins were precipitated in equal volumes of $0.5 \mathrm{~N} \mathrm{NaOH}$ and $10 \% \mathrm{ZnSO}_{4}$ for $15 \mathrm{~min}$ prior to centrifugation at $14,000 \times g$ for $5 \mathrm{~min}$ at $4^{\circ} \mathrm{C}$. Supernatants $(10 \mu \mathrm{L})$ were injected into a reflux column containing $0.1 \mathrm{M} \mathrm{VCl}_{3}$ in $1 \mathrm{M} \mathrm{HCl}$ at $80^{\circ} \mathrm{C}$ to reduce any nitrates and nitrites into $\mathrm{NO}$. NO then combined with $\mathrm{O}_{3}$ produced by the $\mathrm{NO}$ analyser to form $\mathrm{NO}_{2}$. The resulting emission from the excited $\mathrm{NO}_{2}$ was detected by a photomultiplier tube and recorded digitally $(\mathrm{mV})$. The values were then interpolated to a standard curve of $\mathrm{NaNO}_{2}$ concentrations concurrently determined. Sample measurements were made in triplicate for each cell treatment, with each sample injected a minimum of three times for a total of nine readings per data point. Significance was determined by ANOVA.

\section{Cell viability assay}

Media supernatant $(50 \mu \mathrm{L})$ from cell monolayers treated with HDE or media alone was sampled for cell viability assays. In addition, confluent monolayers of cells were lysed as a positive control for lactate dehydrogenase $(\mathrm{LDH})$ release. Cell viability was determined by a commercially available kit (Sigma, St. Louis, 




FIGURE 1. Baseline ciliary beat frequency (CBF) was elevated in airway epithelial cells exposed to hog barn-dust extract (HDE). Monolayers of confluent ciliated bovine bronchial epithelial cells were treated with 5\% HDE (-) or media control $(\square)$ for $\leqslant 5 \mathrm{~h}$, and CBF was measured. Exposure to $5 \% \mathrm{HDE}$ increased CBF by $\sim 1 \mathrm{~Hz}$ versus media control after $1-2 \mathrm{~h}$. *: $p<0.05$.

$\mathrm{MO}$, USA) to measure $\mathrm{LDH}$ release, according to the manufacturer's instructions.

\section{Western blotting}

The solubilised HDE or grain feed dust proteins were separated on SDS-PAGE under reducing conditions and transferred to nitrocellulose as detailed previously [23]. Nitrocellulose membranes were blocked overnight at $4{ }^{\circ} \mathrm{C}$ in a buffer consisting of $5 \%$ milk, $50 \mathrm{mM}$ Tris- $\mathrm{HCl}, 90 \mathrm{mM} \mathrm{NaCl}$ and $2 \mathrm{mM} \mathrm{CaCl}$ (Blotto). The detection of IL-8 was visualised by incubating the blots with a solution of Blotto containing $0.2 \mathrm{mg} \cdot \mathrm{mL}^{-1}$ rabbit anti-porcine IL-8 (R\&D Systems, Minneapolis, MN, USA) and $0.5 \mathrm{mg} \cdot \mathrm{mL}^{-1}$ peroxidase-conjugated goat anti-rabbit secondary antibody (Rockland, Gilbertsville, PA, USA). Blots were washed extensively with phosphate buffered saline (PBS) and Tween-20, washed once with PBS and developed using enhanced chemiluminescence (SuperSignal West Pico, Pierce, Rockford, IL, USA). Controls consisted of probing the blot with a nonspecific rabbit immunoglobulin $(\mathrm{Ig}) \mathrm{G}$ in place of the rabbit anti-porcine IL-8.

\section{ELISA for IL-8}

The concentration of IL-8 in the HDE samples was determined by ELISA as previously reported [15].

\section{Statistical analysis}

All quantitative experiments were performed at least three times with each data point assayed in triplicate $(n=9)$. Data were analysed using Graphpad Prizm (San Diego, CA, USA) and represented as mean \pm SE. Data were analysed for statistical significance using one-way ANOVA for NO assays and a paired t-test for the ciliary beat frequency (CBF) assays. Significance was accepted at the $95 \%$ confidence interval.

\section{RESULTS}

\section{HDE elevated baseline CBF}

Acute exposure to inhaled particles typically stimulates mucociliary clearance, leading to the hypothesis that brief exposure of naïve ciliated cells to HDE would stimulate ciliary motility. To test this hypothesis, the short-term effect of HDE on mucociliary clearance in vitro was determined by exposing ciliated bovine bronchial epithelial cells to HDE and examining cilia motility. Confluent monolayers of ciliated cells were maintained as a submerged culture in M199 media. Cells were treated in the presence or absence of 5\% HDE and CBF assayed for $\leqslant 5 \mathrm{~h}$ at room temperature using SAVA [22]. Exposure to culture media demonstrated a consistent baseline CBF of $\sim 9 \mathrm{~Hz}$ (fig. 1). An elevation in baseline CBF was observed after $30 \mathrm{~min}$ exposure to HDE, with the maximal increase $(\sim 1 \mathrm{~Hz})$ observed after $1 \mathrm{~h}$ treatment with HDE. The effect of HDE on CBF was concentration and time dependent. After $30 \mathrm{~min}$ exposure, increasing concentrations of HDE from 5-25\% elevated the baseline CBF with respect to media control exposure (fig. 2a). While early exposure (30-90 $\mathrm{min}$ ) to 5-25\% HDE resulted in the elevation of CBF, higher concentrations (10-25\%) of HDE did not increase CBF after 2-3 h (fig. 2b). In fact, higher concentrations $(25 \%)$ of HDE produced a sustained slowing of the cilia after $3 \mathrm{~h}$. After longer exposure times, the 25\% HDE was associated with decreased cell viability as determined by LDH release (data not shown). These data show that HDE elevated baseline CBF in bronchial epithelial cells.

Since endotoxin is a known mediator of inflammation due to dust inhalation, it was proposed that the HDE-induced elevation of $\mathrm{CBF}$ was independent of endotoxin. To test this hypothesis, a 5\% dilution of HDE was eluted from a polymyxin B column to reduce the level of endotoxin contained in the sample. This detoxified HDE solution was then exposed to ciliated cells and CBF was measured. No differences in CBF were observed between 5\% HDE exposure and polymyxin-treated HDE exposure (fig. 3a). Control media eluted from a polymyxin B column had no effect on baseline CBF levels compared with media control (data not shown). The amount of endotoxin contained in a 5\% dilution of HDE was determined by the LAL test [21] to be $\sim 40 \mathrm{EU} \cdot \mathrm{mL}^{-1}$. When $40 \mathrm{EU} \cdot \mathrm{mL}^{-1}$ of lipopolysaccharide (LPS) was added directly to ciliated cells, there was no increase in CBF baseline beating (fig. $3 \mathrm{~b}$ ). The addition of $40 \mathrm{EU} \cdot \mathrm{mL}^{-1}$ LPS to $5 \%$ HDE did not alter the elevated CBF observed with 5\% HDE (data not shown). These data provide evidence that endotoxin is not the component of HDE responsible for elevations in baseline CBF.

\section{HDE stimulated NO production}

Exposure to dusts from swine confinement facilities has been associated with elevated exhaled NO [24], and NO production is a known stimulator of CBF [10]. Therefore, it was hypothesised that the effect of HDE on ciliated airway epithelial cells was regulated by NO production. Confluent monolayers of media-submerged ciliated cells were treated in the presence or absence of HDE and media release of NO was assayed for $\leqslant 2 \mathrm{~h}$ at room temperature using a chemiluminescence detector of nitrite and nitrate accumulation. A significant accumulation of $\mathrm{NO}$ into the cell media was observed, beginning after $30 \mathrm{~min}$ exposure to 5\% HDE (fig. 4). Elevations in $\mathrm{NO}$ continued $\leqslant 2 \mathrm{~h}$; after this, no further accumulation was observed. Higher concentrations of HDE $(10-25 \%)$ also elevated NO, but lower HDE concentrations (1\%) did not result in significant elevations (data not shown). Pre-incubation of the cells for $1 \mathrm{~h}$ with $1 \mu \mathrm{M}$ of the NO 

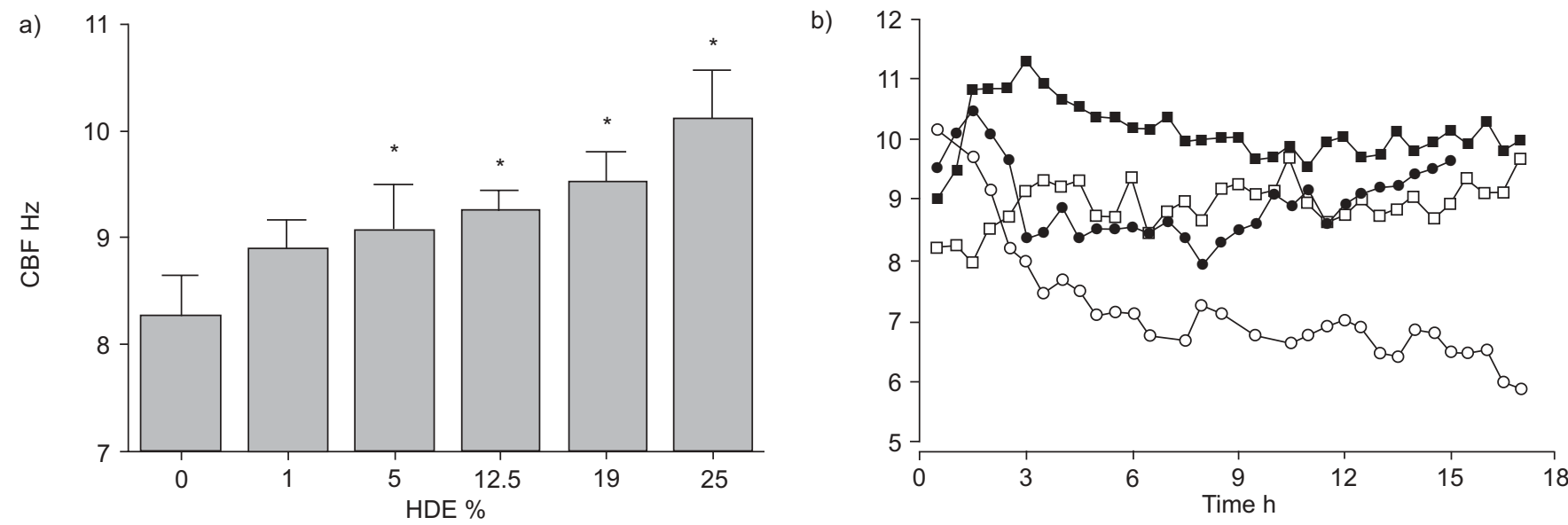

FIGURE 2. The elevation of baseline ciliary beat frequency (CBF) by hog barn-dust extract (HDE) was time and concentration dependent. Ciliated bovine bronchial epithelial cells were treated with 0-25\% dilutions of HDE, and CBF was measured after 30 min and $24 \mathrm{~h}$. a) After 30 min exposure to 5-25\% HDE, the baseline CBF was

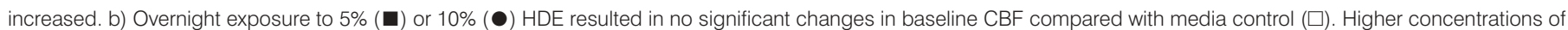
HDE $(25 \% ; \bigcirc)$ resulted in lowered CBF after $4-24 \mathrm{~h}$. *: $p<0.05$

synthase inhibitor, $N^{\mathrm{G}}$-monomethyl-L-arginine (L-NMMA), blocked HDE-stimulated production of NO (data not shown). Likewise, the HDE-stimulated elevations in baseline CBF were blocked when the cells were pre-incubated with L-NMMA (fig. 5). These data reveal that HDE increased the production of $\mathrm{NO}$, a stimulatory regulator of CBF in ciliated cells.

\section{HDE exposure blocked isoproterenol-stimulated CBF}

NO-dependent regulation is important in the response of ciliated cells to $\beta$-agonist-stimulated increases in CBF [25]; therefore, the in vitro effect of HDE exposure on isoproterenol (ISO)-stimulation of cilia beating was examined. Similar to previous findings [26], ISO $(100 \mu \mathrm{M})$ rapidly stimulated a 3-4 Hz increase in CBF after 30-90 $\mathrm{min}$, followed by a subsequent return to or decrease in baseline beating after $2 \mathrm{~h}$ exposure (fig. 6a). This stimulation in response to ISO was blocked when the cells were pre-treated with 5\% HDE for $1 \mathrm{~h}$. Previous studies have shown that IL-8 exposure blocks $\beta$-agonist-stimulated increases in CBF [14] and HDE stimulates the release of IL-8 from bronchial epithelial cells [15]. Therefore, the present authors investigated the role of IL- 8 in this HDE cilia inhibitory response. Pre-incubation of undiluted HDE with $20 \mu \mathrm{g}$ rabbit anti-porcine IL- 8 for $24 \mathrm{~h}$ reversed the inhibitory effect of $5 \%$ HDE on ISO-stimulated increases in CBF (fig. 6b). The presence of anti-porcine IL-8 antibody in HDE produced no differences in CBF compared with HDE alone (data not shown). Isotype control IgG antibody did not restore the ability of ISO to stimulate CBF in the presence of HDE (data not shown). These data demonstrated that the presence of IL-8 in HDE was responsible for the lost responsiveness to ISO stimulation of CBF in ciliated bronchial epithelium.


FIGURE 3. Elevation of ciliary beat frequency (CBF) by hog barn-dust extract (HDE) was not due to endotoxin. a) Ciliated bovine bronchial epithelial cells were treated for $\leqslant 5 \mathrm{~h}$ with media control $(\square), 5 \% \mathrm{HDE}(\bullet)$, or $5 \% \mathrm{HDE}$ eluted from endotoxin-binding polymyxin B column (Detox. 5\% HDE; $\bigcirc$ ), and CBF was measured. Detox. $5 \%$ HDE significantly elevated baseline CBF compared with media control at each time point from 1-4.5 h. No significant differences were observed between $5 \% \mathrm{HDE}$ and Detox. $5 \%$ $\mathrm{HDE}$ at similar time points. b) Addition of $40 \mathrm{EU} \cdot \mathrm{mL}^{-1}$ lipopolysaccharide $(\bigcirc)$ to the cell media resulted in no significant change in CBF compared with media control ( $\square$ ) at any time point assayed. The $5 \% \mathrm{HDE}(\bullet)$ contained $\sim 40 \mathrm{EU} \cdot \mathrm{mL}^{-1}$ endotoxin. *: $\mathrm{p}<0.05$. 




FIGURE 4. Hog barn-dust extract (HDE) stimulated nitric oxide (NO) production in airway epithelial cells. Ciliated bovine bronchial epithelial cells were treated with $5 \% \mathrm{HDE}$ in a nitrogen-free cell media for $\leqslant 2 \mathrm{~h}$. Total increases in media nitrites and nitrates were assayed. Exposure to 5\% HDE rapidly increased the level of accumulated nitrites and nitrates compared with media control, with a sustained increase for $2 h .{ }^{*}: p<0.05$.

\section{HDE contained IL-8}

To identify the presence of IL-8 in hog barn dust, Western blot analysis was performed on samples of HDE. Six different samples of hog barn dust, each from a different farm, were prepared in aqueous solutions as described in the Materials and Methods section. Samples were resolved by polyacrylamide gel electrophoresis and Western blotted using rabbit antiporcine IL-8 antibodies. An $8 \mathrm{kDa}$ protein band was observed in all samples assayed (fig. 7). As a negative control, GFDE demonstrated no porcine IL-8 (data not shown). Using antibodies against porcine IL-8, which recognise bovine IL-8, each of the six different HDE samples contained an average of $258.3 \mathrm{pg} \cdot \mathrm{mL}^{-1}$ of IL-8, as determined by ELISA. These data demonstrate that porcine IL-8 was present in hog barn dust.

\section{DISCUSSION}

In the present study, extracts of hog barn dust increased baseline cilia beating in an in vitro bovine cell model. However, it was also observed that exposure to hog barn dust blocked the ability of a $\beta$-agonist, ISO, to stimulate increased cilia beating. The stimulation of the ciliary "fight or flight" response, as mimicked by $\beta$-agonists, may be more important in mucociliary clearance than maintenance of baseline beating. These observations also underscore that ciliary stimulatory pathways may involve different mechanisms of regulation from the cellular machinery that maintains baseline continual cilia beating.

These observations have potential implications for the effectiveness of $\beta$-agonists in hog confinement-facility workers. PoOlE, et al. [27] have reported that the majority of swine veterinarians with airflow obstruction did not demonstrate reversibility with $\beta$-agonists. Although the mechanisms by which $\beta$-agonists mediate bronchodilation and mucociliary clearance may not be completely identical, the lack of spirometry responsiveness to $\beta$-agonists suggests the possibility that exposure to hog barn dust interferes with the ability

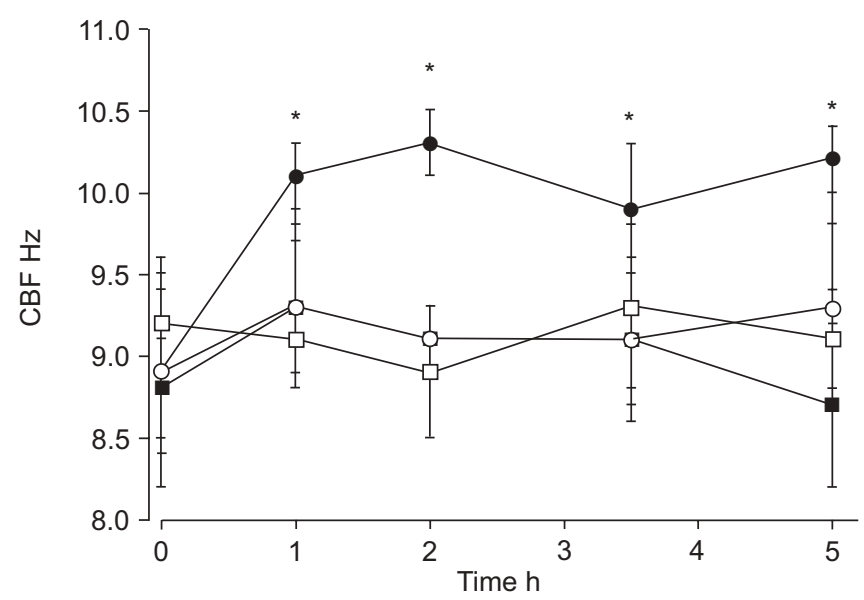

FIGURE 5. Hog barn-dust extract (HDE) stimulation of ciliary beat frequency (CBF) was nitric oxide (NO) dependent. Ciliated bovine bronchial epithelial cells were treated for $\leqslant 5 \mathrm{~h}$ with media control $(\square), 5 \% \mathrm{HDE}(\bullet), 10 \mu \mathrm{M}$ NO synthase inhibitor $N^{G}$-monomethyl-L-arginine (L-NMMA; $\left.\mathbf{\square}\right)$ or 5\% HDE plus $10 \mu \mathrm{M}$ L-NMMA $(\bigcirc)$, and CBF was measured. Baseline CBF was increased with 5\% HDE compared with media control at each time-point, but the HDE-induced elevation was blocked when the cells were pre-treated for $1 \mathrm{~h}$ with L-NMMA. *: $\mathrm{p}<0.05$.

of $\beta$-agonists to regulate airway function, and is consistent with ability of HDE to block ISO-stimulated CBF.

The present data revealed that bronchial epithelial cells generated $\mathrm{NO}$ in response to $\mathrm{HDE}$ exposure in vitro. Similarly, elevated exhaled NO has been reported in normal subjects [24] and workers [28] exposed to swine confinementfacility dust. The present authors found that the increased NO levels were coincident with the elevation of baseline cilia beating in HDE-exposed cells, and HDE effects on beating cilia were blocked by the NO synthase inhibitor L-NMMA. NO is an established regulator of cilia, first reported to control stimulated increases in beating by JAIN et al. [10]. The functional significance of this NO-elevated beating in response to HDE is not clear. The present in vitro studies represent an acute exposure of naïve cells. In fact, longer exposure times to HDE exhibited a return to the same baseline beating as media control-exposed cells. This is in contrast to the rapid effect of HDE on $\beta$-agonist-stimulated cilia beating. However, it would be interesting to explore the effect of swine confinement dust on NO and ciliary beating in naïve subjects. Naïve subjects have a more pronounced inflammatory response of the respiratory tract than swine confinement workers, suggesting that an adaptation to the environment probably develops in workers over time [29].

Exposure to HDE for $1 \mathrm{~h}$ completely blocked ISO stimulation of cilia beating. In exploring the mechanism of this inhibition, the present authors found that neutralising IL-8 levels in the HDE restored the ISO cilia stimulation response. This observation agrees with the previous finding that IL-8 desensitises the $\beta$-agonist response [14]. In that study, it was shown that the mechanism of the IL- 8 inhibitory response was at the level of adenylyl cyclase and was not due to alterations in $\beta$-adrenergic receptor [14]. Studies have shown that particles themselves do not alter the $\beta$-agonist receptor, as human subjects respond to $\beta$-agonist after particle instillation [30]. 

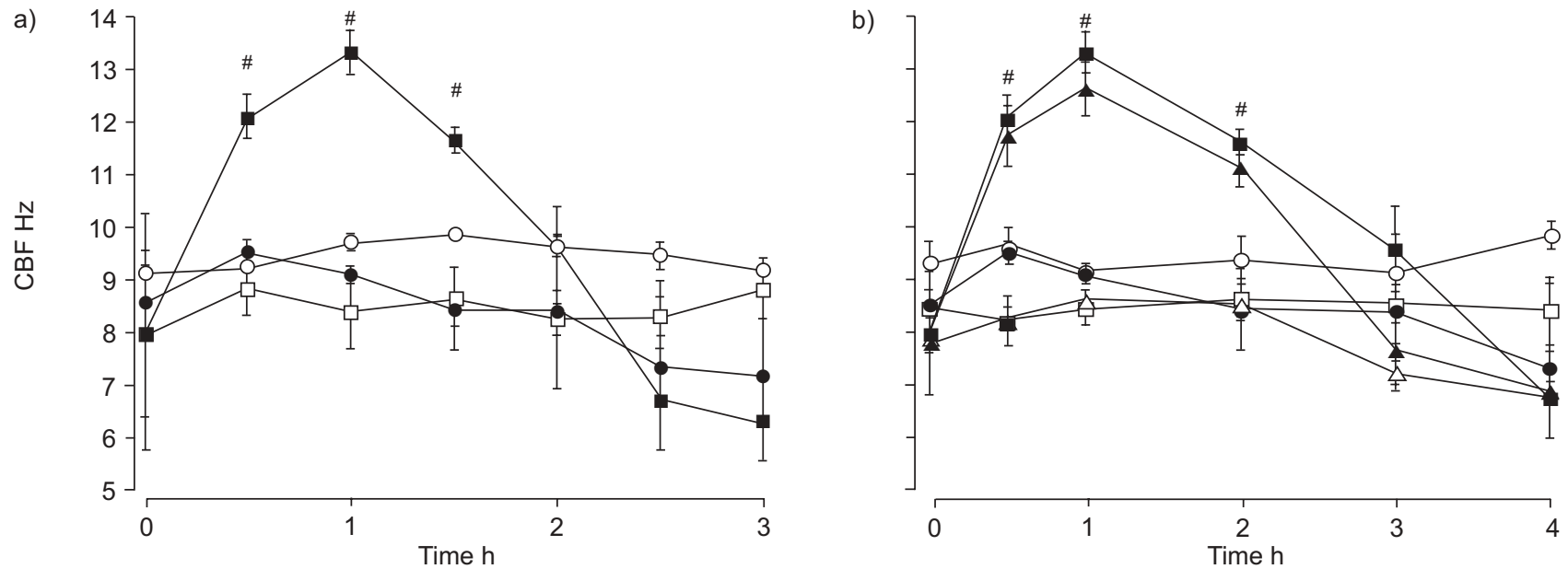

FIGURE 6. Hog barn-dust extract (HDE) inhibition of $\beta$-agonist-stimulated increases in ciliary beat frequency (CBF) was blocked by antibodies to interleukin (IL)-8 Ciliated bovine bronchial epithelial cells were pre-treated with or without a $5 \%$ dilution of HDE for $1 \mathrm{~h}$ prior to exposure to $100 \mu \mathrm{M}$ isoproterenol (ISO) for $\leqslant 4 \mathrm{~h}$. a) ISO plus media (Ш) significantly stimulated increases of 3-4 Hz in CBF compared with media control ( $\square$ ) over a period of 30-90 min exposure. An increase in CBF of $\sim 1 \mathrm{~Hz}$ was caused by $5 \% \mathrm{HDE}(\mathrm{O})$. Pre-incubation with $5 \% \mathrm{HDE}$ blocked the ISO stimulation of CBF $(\bullet)$ and resulted in no changes compared with media control. b) Overnight preincubation of HDE with antibodies to IL-8 (anti-IL-8) restored the ability of ISO to stimulate CBF versus ISO-stimulated cells exposed to HDE and not pre-treated with anti-IL-8. $\triangle$ : anti-IL-8 pre-incubation of HDE; $\mathbf{\Lambda}$ : anti-IL-8 pre-incubation of HDE then exposure to ISO. ${ }^{\#}: \mathrm{p}<0.005$.

While it has been shown that HDE stimulates a significant production and release of IL-8 after $6-48 \mathrm{~h}$ exposure [15], the cilia desensitisation effect occurred after $1 \mathrm{~h}$ HDE exposure in the current study. This rapid effect of desensitisation suggested the presence of IL-8 in dust and this was confirmed by Western blot. However, it is more likely that a sustained $\beta$-agonist



FIGURE 7. Identification of interleukin (IL)-8 in hog barn-dust extract (HDE). a) Six different samples of $\operatorname{HDE}(A-F)$ were resolved by polyacrylamide gel electrophoresis and subjected to Western blotting using antibodies against porcine IL-8. HDE demonstrated a reactive protein band at $\sim 8-9 \mathrm{kDa}$ recognised by anti-IL8 antibodies in all dust samples assayed. b) HDE samples A- $F$ were assayed for IL8 by ELISA. An average (Av) of $258.3 \mathrm{pg} \cdot \mathrm{mL}^{-1} \mathrm{LL}-8$ was detected in the six HDE samples. desensitisation response from HDE would also involve airway epithelium stimulation of IL-8 over a longer period of time.

It is also possible that the short-term organic dust stimulation may be analogous to the $\beta$-agonist stimulation in that it requires a "flight response" for clearance. This may represent a distinct difference from the maintenance of baseline beating as altered by NO. HDE may, therefore, desensitise this flight or stimulation response. Alternatively, HDE may activate bronchial epithelial cell protein kinase C (PKC) [15], which is consistent with the published observations that PKC-activating agents cause slowing of cilia [31]. The HDE-mediated activation of a PKC isoform may result in a ciliary axonemal protein phosphorylation event that leads to the uncoupling of the cilia flight response.

Although the present study has demonstrated that HDE contains IL-8 that contributes to the regulation of CBF, it is possible that other constituents of the dust are also involved. Studies to characterise components of HDE responsible for stimulation of airway epithelial cell IL-8 release are ongoing. The component(s) of HDE mediating IL-8 release appears to be a large molecule(s) that is stable upon boiling, acid and base treatment (data not shown). Further work is required to determine the specific nature of these large molecules that induce IL-8 production and whether these molecules also directly regulate baseline or ISO-stimulated ciliary beating.

In conclusion, dysfunction in mucociliary clearance occurs in workers chronically exposed to swine confinement operation environments. The mechanism of this dysfunction is complex. Dust extracts from these facilities alter ciliary beat at baseline and significantly diminish the $\beta$-agonist-enhanced beat frequency. In part, nitric oxide mediates this process. In addition, a novel component, interleukin-8, was found in the dust extract, which may explain the observed rapid changes in mucociliary clearance. 


\section{REFERENCES}

1 Cole D, Todd L, Wing S. Concentrated swine feeding operations and public health: a review of occupational and community health effects. Environ Health Perspect 2000; 108: 685-699.

2 Donham KJ, Reynolds SJ, Whitten P, Merchant JA, Burmeister L, Popendorf WJ. Respiratory dysfunction in swine production facility workers: dose-response relationships of environmental exposures and pulmonary function. Am J Ind Med 1995; 27: 405-418.

3 Zejda JE, Barber E, Dosman JA, et al. Respiratory health status in swine producers relates to endotoxin exposure in the presence of low dust levels. J Occup Med 1994; 36: 49-56.

4 Von Essen S, Donham K. Illness and injury in animal confinement workers. Occup Med 1999; 14: 337-350.

5 Preller L, Heederik D, Boleij JS, Vogelzang PF, Tielen MJ. Lung function and chronic respiratory symptoms of pig farmers: focus on exposure to endotoxins and ammonia and use of disinfectants. Occup Environ Med 1995; 52: 654-660.

6 Wang Z, Larsson K, Palmberg L, Malmberg P, Larsson P, Larsson L. Inhalation of swine dust induces cytokine release in the upper and lower airways. Eur Respir J 1997; 10: 381-387.

7 Cormier Y, Duchaine C, Israel-Assayag E, Bedard G, Laviolette M, Dosman J. Effects of repeated swine building exposures on normal naive subjects. Eur Respir J 1997; 10: 1516-1522.

8 Snyder MC, Leopold DA, Chiu BC, Von Essen SG, Liebentritt $\mathrm{N}$. The relationship between agricultural environments and olfactory dysfunction. I Agric Saf Health 2003; 9: 211-219.

9 Wanner A, Salathé M, O’Riordan TG. Mucociliary clearance in the airways. Am J Respir Crit Care Med 1996; 154: 1868-1902.

10 Jain B, Rubinstein I, Robbins RA, Leise KL, Sisson JH. Modulation of airway epithelial cell ciliary beat frequency by nitric oxide. Biochem Biophys Res Commun 1993; 191: 83-87.

11 Wyatt TA, Forget MA, Adams JM, Sisson JH. Both cAMP and CGMP are required for maximal ciliary beat stimulation in a cell-free model of bovine ciliary axonemes. Am J Physiol Lung Cell Mol Physiol 2005; 288: L546-L551.

12 Verdugo P, Johnson NT, Tam PY. $\beta$-Adrenergic stimulation of respiratory ciliary activity. J Appl Physiol 1980; 48: 868-871.

13 Wyatt TA, Sisson JH. Chronic ethanol downregulates PKA activation and ciliary beating in bovine bronchial epithelial cells. Am J Physiol Lung Cell Mol Physiol 2001; 281: L575-L581.

14 Allen-Gipson DS, Romberger DJ, Forget MA, May KL, Sisson JH, Wyatt TA. IL-8 inhibits isoproterenol-stimulated ciliary beat frequency in bovine bronchial epithelial cells. J Aerosol Med 2004; 17: 107-115.

15 Romberger DJ, Bodlak V, Von Essen SG, Mathisen T, Wyatt TA. Hog barn dust extract stimulates IL-8 and IL-6 release in human bronchial epithelial cells via PKC activation. J Appl Physiol 2002; 93: 289-296.
16 Wyatt TA, Forget MA, Sisson JH. Ethanol stimulates ciliary beating by dual cyclic nucleotide kinase activation in bovine bronchial epithelial cells. Am J Pathol 2003; 163: 1157-1166.

17 Wang Z, Malmberg P, Ek A, Larsson K, Palmberg L. Swine dust induces cytokine secretion from human epithelial cells and alveolar macrophages. Clin Exp Immunol 1999; 115: 6-12.

18 Von Essen SG, O'Neill DP, Olenchok SA, Robbins RA, Rennard SI. Grain dusts and grain plant components vary in their ability to recruit neutrophils. J Toxicol Environ Health 1995; 46: 425-441.

19 Mueller-Anneling LJ, O'Neill ME, Thorne PS. Biomonitoring for assessment of organic dust-induced lung inflammation. Eur Respir J 2006; 27: 1096-1102.

20 Lee SA, Adhikari A, Grinshpun SA, McKay R, Shukla R, Reponen T. Personal exposure to airborne dust and microorganisms in agricultural environments. J Occup Environ Hyg 2006; 3: 118-130.

21 Rojas-Corona RR, Skarnes R, Tamakuma S, Fine J. The Limulus coagulation test for endotoxin. A comparison with other assay methods. Proc Soc Exp Biol Med 1969; 132: 599-601.

22 Sisson JH, Stoner JA, Ammons BA, Wyatt TA. All-digital image capture and whole-field analysis of ciliary beat frequency. J Microsc 2003; 211: 103-111.

23 Laemmli UK. Cleavage of structural proteins during the assembly of the head of bacteriophage T4. Nature 1970; 277: 680-685.

24 Kirsten AM, Jorres RA, Kirsten D, Magnussen H. Effect of a nasal challenge with endotoxin-containing swine confinement dust on nasal nitric oxide production. Eur J Med Res 1997; 2: 335-339.

25 Sisson JH, May K, Wyatt TA. Nitric oxide-dependent ethanol stimulation of ciliary motility is linked to CAMPdependent protein kinase (PKA) activation in bovine bronchial epithelium. Alcohol Clin Exp Res 1999; 23: 1528-1533.

26 Wyatt TA, Spurzem JR, May K, Sisson JH. Regulation of ciliary beat frequency by both PKA and PKG in bovine airway epithelial cells. Am J Physiol 1998; 275: L827-L835.

27 Poole JA, LeVan TD, Slager RE, et al. Bronchodilator responsiveness in swine veterinarians. J Agromedicine 2007; 12: $49-54$.

28 Von Essen SG, Scheppers LA, Robbins RA, Donham KJ. Respiratory tract inflammation in swine confinement workers studied using induced sputum and exhaled nitric oxide. J Toxicol Clin Toxicol 1998; 36: 557-565.

29 Von Essen S, Romberger D. The respiratory inflammatory response to the swine confinement building environment: the adaptation to respiratory exposures in the chronically exposed worker. J Agric Saf Health 2003; 9: 185-196.

30 Fazio F, Lafortuna C. Effect of inhaled salbutamol on mucociliary clearance in patients with chronic bronchitis. Chest 1981; 80: 827-830.

31 Wyatt TA, Schmidt SC, Rennard SI, Sisson JH. Acetaldehyde-stimulated PKC activity in airway epithelial cells treated with smoke extract from normal and smokeless cigarettes. Proc Soc Exp Biol Med 2000; 225: 91-97. 